\title{
Synaptobrevin N-terminally bound to syntaxin- SNAP-25 defines the primed vesicle state in regulated exocytosis
}

\author{
Alexander M. Walter, ${ }^{1}$ Katrin Wiederhold, ${ }^{2}$ Dieter Bruns, ${ }^{3}$ Dirk Fasshaver, ${ }^{2}$ and Jakob B. Sørensen ${ }^{1,4}$ \\ 'Molecular Mechanism of Exocytosis, Department of Membrane Biophysics and ${ }^{2}$ Structural Biochemistry, Department of Neurobiology, Max Planck Institute for Biophysical \\ Chemistry, D-37077 Göttingen, Germany \\ ${ }^{3}$ Department of Physiology, University of Saarland, D-66424 Homburg/Saar, Germany \\ ${ }^{4}$ Department of Neuroscience and Pharmacology, Faculty of Health Sciences, University of Copenhagen, 2200 Copenhagen N, Denmark
}

$\mathrm{R}$ apid neurotransmitter release depends on the ability to arrest the SNAP receptor (SNARE)-dependent exocytosis pathway at an intermediate "cocked" state, from which fusion can be triggered by $\mathrm{Ca}^{2+}$. It is not clear whether this state includes assembly of synaptobrevin (the vesicle membrane SNARE) to the syntaxinSNAP-25 (target membrane SNAREs) acceptor complex or whether the reaction is arrested upstream of that step. In this study, by a combination of in vitro biophysical measurements and time-resolved exocytosis measurements in adrenal chromaffin cells, we find that mutations of the

\section{Introduction}

Rapid release of water-soluble signaling molecules through fusion of vesicles with the plasma membrane underlies most cell to cell communication in higher animals, including synaptic transmission (Südhof, 2004). The decisive property of the protein machinery driving fast exocytosis is the ability to arrest the process at an intermediate, release-ready or "cocked" state while blocking premature fusion. Upon $\mathrm{Ca}^{2+}$ influx, membrane fusion of release-ready vesicles proceeds to completion within a fraction of a millisecond. Much current research aims at identifying the molecular configuration of the intermediate state.

The neuronal SNARE complex (Söllner et al., 1993) is formed between a vesicular protein, synaptobrevin-2 (syb-2)/ VAMP-2 (Baumert et al., 1989; Elferink et al., 1989) and an acceptor complex consisting of two plasma membrane proteins, syntaxin-1 (Bennett et al., 1992) and SNAP-25 (Oyler et al.,

Correspondence to Jakob B. Sørensen: jakobbs@sund.ku.dk

K. Wiederhold's present address is Medical Research Council Laboratory of Molecular Biology, Cambridge CB2 OQH, England, UK.

Abbreviations used in this paper: ANOVA, analysis of variance; $C D$, circular dichroism; ITC, isothermal calorimetry; RRP, readily releasable pool; SAF, standalone foot; SRP, slowly releasable pool; WT, wild type.
$\mathrm{N}$-terminal interaction layers of the SNARE bundle inhibit assembly in vitro and vesicle priming in vivo without detectable changes in triggering speed or fusion pore properties. In contrast, mutations in the last C-terminal layer decrease triggering speed and fusion pore duration. Between the two domains, we identify a region exquisitely sensitive to mutation, possibly constituting a switch. Our data are consistent with a model in which the $\mathrm{N}$ terminus of the SNARE complex assembles during vesicle priming, followed by $\mathrm{Ca}^{2+}$-triggered C-terminal assembly and membrane fusion.
1989; for reviews see Jahn and Scheller, 2006; Malsam et al., 2008; Rizo and Rosenmund, 2008; Südhof and Rothman, 2009). The resulting extended parallel bundle has the transmembrane anchors of both syb-2 and syntaxin-1 localized at the C-terminal end (Hanson et al., 1997b; Sutton et al., 1998), which prompted the idea that sequential SNARE complex assembly in the N- to C-terminal direction would lead to membrane fusion (Hanson et al., 1997a).

Several studies indicate that the t-SNARE syntaxin-1 (de Wit et al., 2006; Hammarlund et al., 2007; Gerber et al., 2008) and the partner S/M protein Munc18-1 (Voets et al., 2001b; Weimer et al., 2003; Gulyás-Kovács et al., 2007) are both involved in docking vesicles to the plasma membrane. Very recently it was found that the $\mathrm{Ca}^{2+}$ sensor synaptotagmin-1 (syt-1) induces docking of dense-core vesicles, probably by binding to a syntaxin-SNAP-25 dimer on the plasma membrane (de Wit et al., 2009). Other studies indicate that syb-2 is not involved in

(c) 2010 Walter et al. This article is distributed under the terms of an AttributionNoncommercial-Share Alike-No Mirror Sites license for the first six months after the publication date (see http://www.jcb.org/misc/terms.shtml). After six months it is available under a Creative Commons License (Attribution-Noncommercial-Share Alike 3.0 Unported license, as described at http://creativecommons.org/licenses/by-nc-sa/3.0/). 
Figure 1. Overview of mutations introduced into syb-2 in the present investigation. All targeted sites are layer residues facing the inside of the complex (Fasshaver et al., 1998) either at the $\mathrm{N}$-terminal end (left) or at the $\mathrm{C}$-terminal end (right) of the complex. In the LATA mutant, aa 32 (leucine) and aa 35 (threonine) corresponding to layers -7 and -6 were mutated to alanine. The VAVA mutant bears mutations in layers -5 and -4 , where valines (residues 39 and 42 ) were mutated to alanines. In the C-terminal half of the complex, leucine-70 was mutated to alanine (L7OA) and phenylalanine was mutated to alanine (F77A) in layers 4 and 6, respectively. In layer 8 , leucine was substituted by alanine (L84A), arginine (L84N), glycine (L84G), or aspartate (L84D).

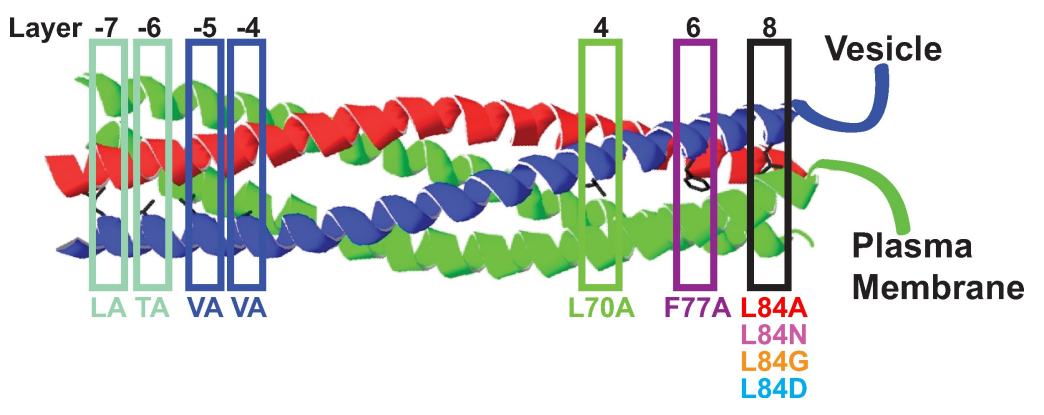

dense-core vesicle docking (Broadie et al., 1995; Borisovska et al., 2005; Gerber et al., 2008), even though the situation is not entirely clear, owing to the use of different docking definitions in this field and possible mechanistic differences between synaptic and dense-core vesicle docking (Verhage and Sørensen, 2008). Overall, a picture is emerging in which vesicles associate with t-SNAREs, whereas synaptobrevin joins later. This raises the question at which stage the process is arrested before $\mathrm{Ca}^{2+}$ influx: at the level of the syntaxin-SNAP-25 dimer upstream of synaptobrevin nucleation or at a later step, in which the $\mathrm{N}$-terminal part of synaptobrevin has already joined the complex? This question cannot be answered based on available data, as has recently been pointed out (Stein et al., 2007). Mutagenesis of SNAP-25 in chromaffin cells revealed that C-terminal mutations interfered with fast $\mathrm{Ca}^{2+}$-dependent triggering of vesicle fusion, whereas mutations in the middle of the complex affected vesicle priming, the upstream process leading to the releaseready state (Sørensen et al., 2006). However, the middle mutations might have affected processes upstream of synaptobrevin binding (de Wit et al., 2009). In vitro studies have shown that SNAREs can fuse vesicle populations, but generally this happens in a nonregulated fashion (Weber et al., 1998; Schuette et al., 2004), and even though recent data suggest that fusion can be arrested by synaptotagmin after initial trans-SNARE pairing (Chicka et al., 2008), it is unclear whether this system can be generalized to the in vivo situation (Stein et al., 2007). Another protein thought to be involved in generating the intermediate, clamped state is complexin. Because both synaptotagmin and complexin interact with the ternary SNARE complexes (Chen et al., 2002; Tang et al., 2006; Dai et al., 2007), this could be taken as evidence that the intermediate state involves synaptobrevin already bound to syntaxin-SNAP-25. However, interactions of these proteins with syntaxin (Bennett et al., 1992; Li et al., 1995; Wu et al., 1999), SNAP-25 (Schiavo et al., 1997; Zhang et al., 2002), or the syntaxin-SNAP-25 complex (Rickman and Davletov, 2003; Bhalla et al., 2006; Guan et al., 2008; Weninger et al., 2008) have also been identified.

In this study, we directly addressed the timing of synaptobrevin association to the fusion machinery. By correlating biochemical equilibrium binding data with physiological measurements of exocytosis, we conclude that most of the synaptobrevin SNARE bundle forms during the process that leads to the formation of the release-ready state of the vesicle. Only the most C-terminal SNARE interaction layers were involved in fusion triggering and fusion pore formation, indicating that a relatively small conformational change might suffice to drive the fusion of release-ready vesicles.

\section{Results}

Mutagenesis of syb-2

To characterize the timing of SNARE complex assembly in the process of neurotransmitter release, we used a mutagenesis approach. We weakened SNARE interactions of syb-2/VAMP-2 regionally by introducing destabilizing point mutations along its binding motif, targeting amino acids contributing to the hydrophobic interaction layers (Fig. 1). In most cases, we used alanine substitutions. Considering the known structure of the SNARE complex, alanines were not expected to prevent binding of synaptobrevin to syntaxin-SNAP-25 or cause clashes in the structure but would probably mildly destabilize the complex. The effects of these mutations were then tested in vitro for their effect on complex stability and assembly rate and in vivo for their effect on neurotransmitter release.

Two sets of mutations were generated: the contribution of the N-terminal part of the synaptobrevin SNARE motif to triggered exocytosis was studied by use of two mutants bearing double point mutations in the most $\mathrm{N}$-terminal and adjacent layers. In one mutant, syb-2 residues leucine-32 (L) and treonine-35 $(\mathrm{T})$ of layers -7 and -6 were both changed to alanines, thus creating the "LATA" mutant. In layers -5 and -4 , valine-39 and -42 were mutated to alanines to create the "VAVA" mutant (Fig. 1). The other set of mutations tested the contribution of the C-terminal end of the complex by introducing single point mutations into layers 4,6 , and 8 , where alanines were used to replace a leucine (L70A), a phenylalanine (F77A), and a leucine (L84A), respectively.

\section{Biophysical characterization of mutants}

Assembly of a ternary complex such as the SNARE complex must involve at least two steps. Data from both in vitro (Hayashi et al., 1994; Fasshauer et al., 1997; Pobbati et al., 2006) and cellular systems (An and Almers, 2004; Rickman et al., 2004; Halemani et al., 2009) show that the first step is SNAP-25 binding to syntaxin, forming a 1:1 acceptor complex on the plasma membrane. The second step comprises binding of synaptobrevin to this acceptor complex, thus forming the full SNARE complex. A complication of these studies is that the 1:1 syntaxinSNAP-25 acceptor complex tends to bind to a second syntaxin in vitro, blocking the synaptobrevin-binding site (Fasshauer and Margittai, 2004). To isolate the synaptobrevin-binding step, a C-terminal fragment of synaptobrevin has been used, which prevents the binding of a second syntaxin while keeping the $\mathrm{N}$-terminal part of the complex accessible (the so-called $\Delta \mathrm{N}$ 

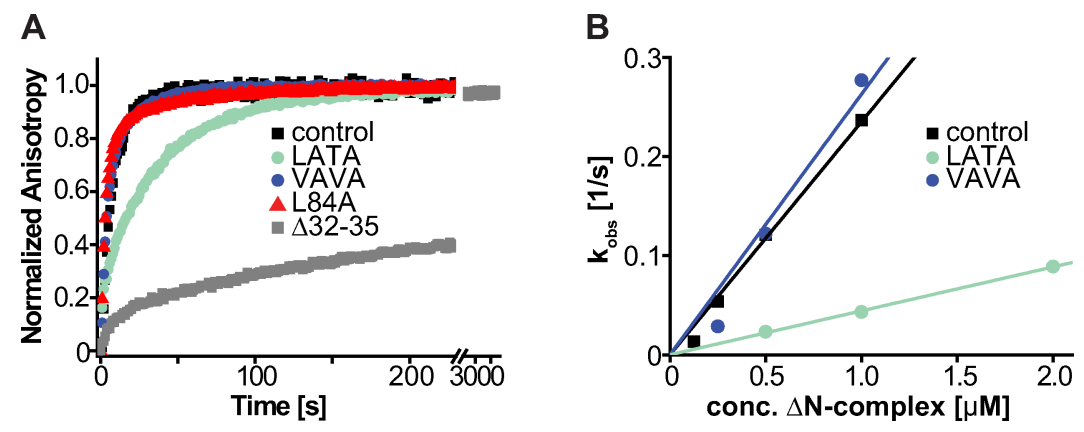

Figure 2. In vitro binding of syb-2 to a syntaxin-SNAP-25 acceptor complex. (A) Fluorescence anisotropy measurements of labeled syb-2 mutants and WT protein binding to the $\Delta \mathrm{N}$ complex. Comparison of two $\mathrm{N}$-terminal mutants (LATA and VAVA) with WT syb-2 (control) and a C-terminal mutant (L84A) is shown. An N-terminally truncated syb-2 ( $\Delta 32-35$, deletion of aa 32-35) displays greatly decreased binding kinetics (note the axis break on the abscissa; $100 \mathrm{nM}$ synaptobrevin was added to $500 \mathrm{nM}$ $\Delta \mathrm{N}$ complex). (B) A plot of the observed binding rates of the synaptobrevin WT protein (control trace) and the LATA and VAVA mutants against the different concentrations (conc.) of the acceptor $\Delta \mathrm{N}$ complex allows calculation of the association rate (slope of linear fits; values given in Biophysical characterization of mutants). complex). Full-length synaptobrevin can bind to the $\Delta \mathrm{N}$ complex and displace the C-terminal fragment. This strategy greatly accelerates SNARE complex formation and liposome fusion in vitro (Pobbati et al., 2006). These binding steps have been thoroughly dissected in vitro, using a combination of purified proteins/peptides and biophysical methods (Pobbati et al., 2006; Wiederhold and Fasshauer, 2009). It was concluded that synaptobrevin prefers to bind to the 1:1 syntaxin-SNAP-25 acceptor complex through $\mathrm{N}$-terminal interaction. However, whether this conclusion can be generalized to the situation in the cell, where other factors must be responsible for keeping the 1:1 acceptor complex in the receptive conformation, remains to be established. In this study, we first characterized some of our mutations using the previously published in vitro methods (Fasshauer and Margittai, 2004; Wiederhold and Fasshauer, 2009).

As expected, alanine substitutions at either the C- or the $\mathrm{N}$-terminal end of the complex did not eliminate the ability of syb-2 to create ternary SNARE complexes. Circular dichroism (CD) spectroscopy revealed that assembled complexes were only slightly destabilized as compared with wild-type (WT) complexes (Fig. S1 A). With the intention of testing how our mutants affect the kinetics of SNARE complex assembly in vitro, we used fluorescence anisotropy measurements and analyzed the speed of synaptobrevin binding to the $\Delta \mathrm{N}$ complex. For these experiments, we used syntaxin-1 lacking the N-terminal $\mathrm{H}_{\mathrm{abc}}$ domain. The $\mathrm{H}_{\mathrm{abc}}$ domain is not part of the SNARE bundle itself, but it reduces the overall speed of assembly by inducing an intermittent shift to the closed conformation of syntaxin-1 (Dulubova et al., 1999; Margittai et al., 2003). The absence of this domain is not expected to change the mechanism of assembly itself. We found that destabilization of the two most N-terminal layers (LATA mutant) of the SNARE complex reduced the speed of synaptobrevin binding to the acceptor complex, whereas no effect could be seen by mutations at the C-terminal end (L84A; Fig. 2 A). Titrating with increasing amounts of $\Delta \mathrm{N}$ complex (Fig. 2 B), we estimated an association rate constant of $235,000 \mathrm{M}^{-1} \mathrm{~s}^{-1}$ (pseudo first-order rate constant) for WT synaptobrevin, which is in reasonable agreement with recent findings (Pobbati et al., 2006). This rate was decreased fivefold by the LATA mutant $\left(44,000 \mathrm{M}^{-1} \mathrm{~s}^{-1}\right)$ but was essentially unchanged for the VAVA mutant $\left(263,000 \mathrm{M}^{-1} \mathrm{~s}^{-1}\right)$. Thus, apparently, the integrity of layers -7 and -6 is essential for rapid binding in vitro. This was confirmed by testing the deletion mutant $\Delta 32-35$, in which 4 aa, including these two layer residues, were deleted; this mutant displayed very slow binding kinetics $\left(<3,000 \mathrm{M}^{-1} \mathrm{~s}^{-1}\right.$, which could not be measured accurately because of the lack of saturation; Fig. 2 A). In contrast, deleting the entire C-terminal half of the SNARE motif (Syb1-52, a deletion of 47 aa) only decreased the binding rate to $123,000 \mathrm{M}^{-1} \mathrm{~s}^{-1}$ (Wiederhold and Fasshauer, 2009). Thus, there can be little doubt (also in light of previous in vitro data [Pobbati et al., 2006]) that the N-terminal end serves to initiate binding of synaptobrevin to the syntaxinSNAP-25 dimer in vitro.

To characterize the thermodynamical properties of the mutants used in this investigation, we made use of isothermal calorimetry (ITC; Wiederhold and Fasshauer, 2009). We found that the LATA mutant decreased the affinity of synaptobrevin to SNARE partners from a dissociation constant $\left(K_{\mathrm{d}}\right)$ of $\sim 2 \mathrm{nM}$ (Wiederhold and Fasshauer, 2009) to $\sim 44 \mathrm{nM}$, whereas the VAVA mutant had a milder but clearly distinguishable phenotype on the dissociation constant ( $K_{\mathrm{d}}$ of $\sim 8 \mathrm{nM}$; Table I). These data confirm that both $\mathrm{N}$-terminal mutations interfere with the binding of synaptobrevin to the syntaxin-SNAP-25 acceptor complex. Again, it is interesting to compare these values with previous results showing that the deletion of the entire C-terminal portion of the SNARE motif (Syb1-65, a deletion of $31 \mathrm{aa}$ ) only increased the $K_{\mathrm{d}}$ to $5.7 \mathrm{nM}$ (Wiederhold and Fasshauer, 2009). The N-terminal end of the synaptobrevin SNARE domain seems crucial for both binding rate and affinity of the interaction.

\section{N-terminal destabilization}

To test the effect of the mutations on exocytosis, we made use of adrenal chromaffin cells, which are widely used as a convenient model system (Neher, 2006). By means of $\mathrm{Ca}^{2+}$ uncaging directly in the cell, it is possible to fuse all vesicles residing in two releasable pools, the readily releasable pool (RRP) and the slowly releasable pool (SRP; Voets et al., 1999). Exocytosis was monitored by membrane capacitance measurements (Lindau and Neher, 1988) and carbon fiber amperometry (Wightman et al., 1991). Kinetic analysis was used to identify the vesicle pool sizes and their fusion kinetics. After the emptying of the pools, exocytosis persists at a sustained rate because of the priming of new vesicles for release, followed immediately by fusion as long as the $\mathrm{Ca}^{2+}$ concentration stays high. Thus, chromaffin cells allow the measurement of fusion kinetics, pool sizes, and priming rates in a single experiment. Because vesicular priming precedes fusion, the chromaffin cell offers a stage-specific assay 
Table I. Thermodynamic properties of $\mathrm{N}$-terminal mutations used, as determined by ITC

\begin{tabular}{|c|c|c|c|c|c|}
\hline $\begin{array}{l}\text { Protein interaction } \\
\text { (cell + syringe) }\end{array}$ & $K_{\mathrm{d}}$ & $\Delta \mathbf{H}$ & $-\mathrm{T} \Delta \mathrm{S}$ & $\Delta \mathbf{G}$ & $\mathbf{N}$ \\
\hline & $n M$ & $\mathrm{kcal} / \mathrm{mol}$ & $\mathrm{kcal} / \mathrm{mol}$ & $\mathrm{kcal} / \mathrm{mol}$ & \\
\hline$\Delta \mathrm{N}$ complex + Syb $1-96^{\mathrm{a}}$ & $2.1 \pm 0.6$ & $-29.9 \pm 0.3$ & 18.1 & -11.8 & 1.05 \\
\hline$\Delta \mathrm{N}$ complex + Syb F77A & $0.8 \pm 0.4$ & $-18.8 \pm 0.2$ & 6.4 & -12.4 & 0.99 \\
\hline$\Delta \mathrm{N}$ complex + Syb LATA & $44.1 \pm 12.3$ & $-16.6 \pm 0.4$ & 6.5 & -10.1 & 1.01 \\
\hline$\Delta \mathrm{N}$ complex + Syb VAVA & $8.4 \pm 2.8$ & $-23.4 \pm 0.4$ & 12.3 & -11.1 & 1.02 \\
\hline
\end{tabular}

$K_{d}$, dissociation constant; $\Delta \mathrm{H}$, binding enthalpy; $\mathrm{T}$, absolute temperature in Kelvin; $\Delta \mathrm{S}$, entropy change; $\Delta \mathrm{G}$, free energy; $\mathrm{N}$, stoichiometry.

aThese data are from Wiederhold and Fasshaver (2009).

in which the effect of manipulations on sequential steps of the exocytotic pathway can be accurately assessed.

We used chromaffin cells from syb-2 (Schoch et al., 2001)/cellubrevin (Yang et al., 2001) double knockout mice as a background for our study. Previous experiments showed that in chromaffin cells, cellubrevin substitutes for syb-2 in its absence, which necessitates the use of double knockout mice (Borisovska et al., 2005). Whereas exocytosis in double knockout cells was abolished, viral expression of syb-2 restored both the kinetics and amplitude of secretion (Borisovska et al., 2005; Kesavan et al., 2007; unpublished data). Therefore, we used double knockout cells rescued with the WT syb-2 construct as the control condition in our experiments. To control for preparation differences, WT rescue was performed in parallel for each preparation included in this study. All constructs studied in these experiments (including the WT syb-2) led to $>10$-fold overexpression above endogenous levels, as shown by quantitative immunostaining of expressing double knockout cells (Fig. S2). Costaining against the vesicular $\mathrm{Ca}^{2+}$ sensor syt-1 revealed similar staining intensities for all constructs as in double knockout cells (Fig. S2), indicating that other vesicular proteins of the cells remained unaffected.

Both synaptobrevin mutants harboring mutations at the $\mathrm{N}$-terminal end of the SNARE motif (LATA and VAVA mutants) showed partial rescue of secretion, but the overall amplitude of the response was reduced (Fig. $3 \mathrm{Ai}$ ). A more detailed view of the kinetics of release was obtained by normalization of the three traces (WT, LATA, and VAVA) to their respective amplitudes at $0.5 \mathrm{~s}$ after $\mathrm{Ca}^{2+}$ photorelease. The fact that all three traces overlapped after normalization demonstrates that the phenotype observed here is selective for the magnitude, but without effect on the kinetics of membrane fusion itself (Fig. 3 Aii). This was also shown by a kinetic analysis of capacitance traces, which was performed by fitting a sum of two exponential functions to the burst phase $(0.5-1.5 \mathrm{~s})$ of secretion. This analysis provided parameters describing the distinct pools (with amplitudes representing pool sizes and time constants reporting on fusion kinetics) involved in transmitter release from chromaffin cells (Fig. 3, Bi and Bii). N-terminal destabilization significantly reduced the amount of vesicles residing in the RRP and
Figure 3. N-terminal mutants of syb-2 reduce pool size and sustained component when expressed in adrenal chromaffin cells. The $\mathrm{N}$-terminal mutants of syb-2 are shown in Fig. 1. (Ai) N-terminal SNARE destabilization shows a reduced secretory response in exocytosis evoked by $\mathrm{Ca}^{2+}$ uncaging. (top) Mean \pm SEM of intracellular $\mathrm{Ca}^{2+}$ concentration after UV. induced $\mathrm{Ca}^{2+}$ uncaging at time $=0.5 \mathrm{~s}$. (middle) Mean capacitance increase. (bottom) Mean amperometric current (thick traces; left ordinate) and amperometric charge (thin traces; right ordinate). All cells were from double syb-2/ cellubrevin knockout mice; control cells were infected with the WT protein (WT rescue). (Aii) A detailed view of normalized traces in Ai shows that the kinetics of release are unaffected (normalized capacitance, thick traces; and normalized amperometric charge, thin traces). (Bi and Bii) Kinetic analysis reveals significant reduction of pool sizes in LATA and VAVA mutants but no effect on rate of release. Fitting of exponentials to capacitance responses was used to quantify parameters reflecting time constants (Bi) and sizes (Bii) of the RRP and SRP. The sustained component (sust.) was found as the slope of the capacitance trace between 1.5 and $5.5 \mathrm{~s}$. Mean \pm SEM is shown (WT rescue, $n=21$ cells; LATA, $n=20$ cells; and VAVA, $n=29$ cells; and $*, P<0.05 ; * *, P<0.01$; and $* * *, P<0.001$ in $t$ test).

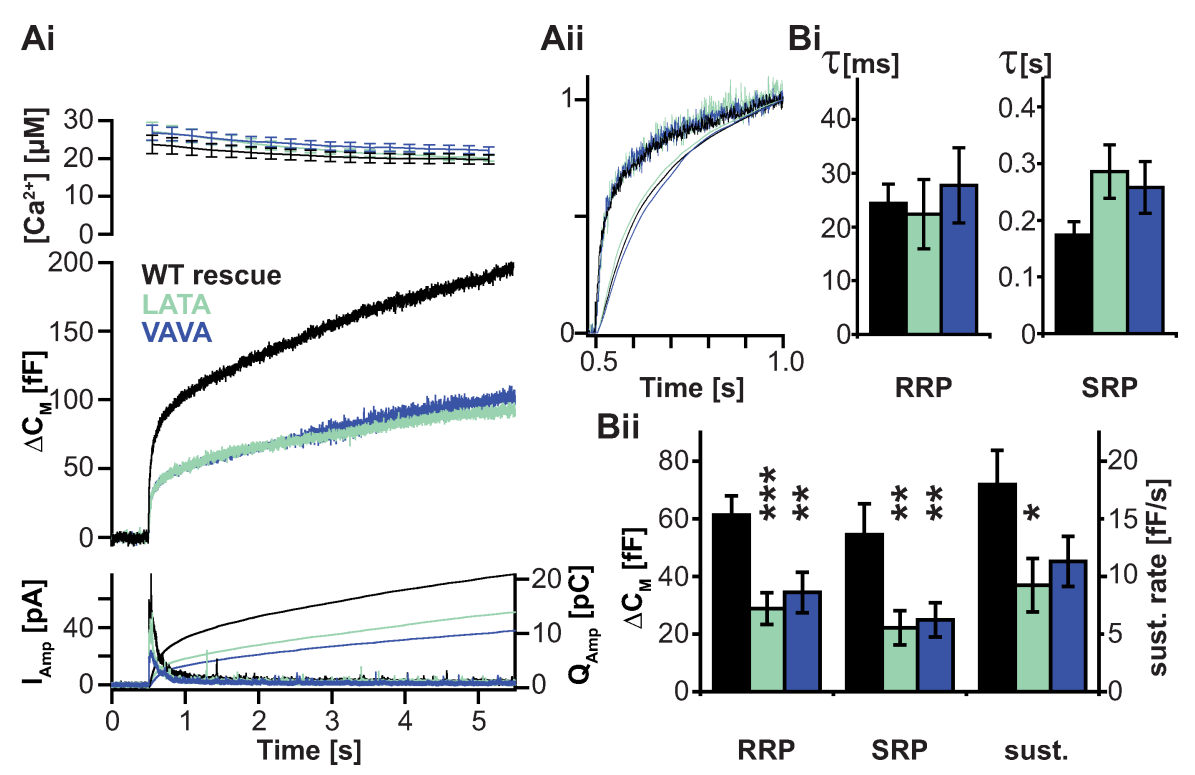


Ai
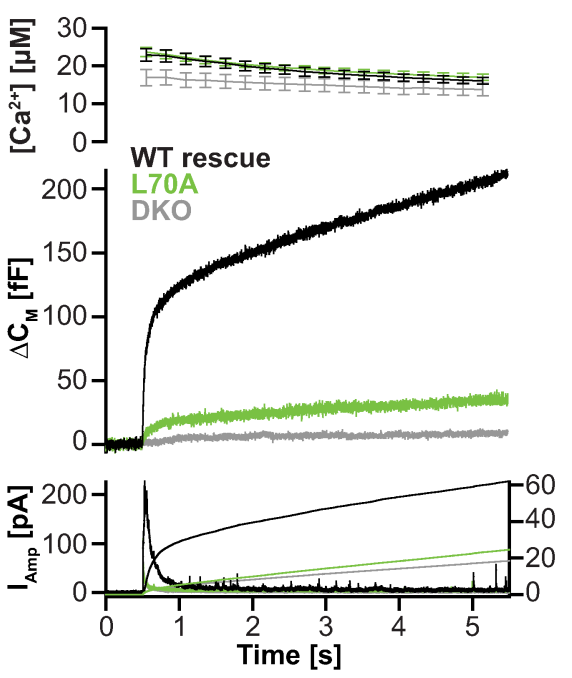

Aii

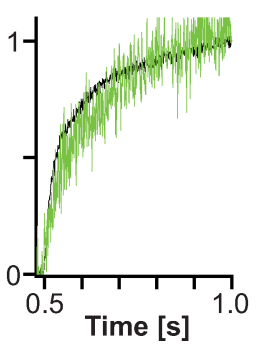

$\mathrm{Bi}$

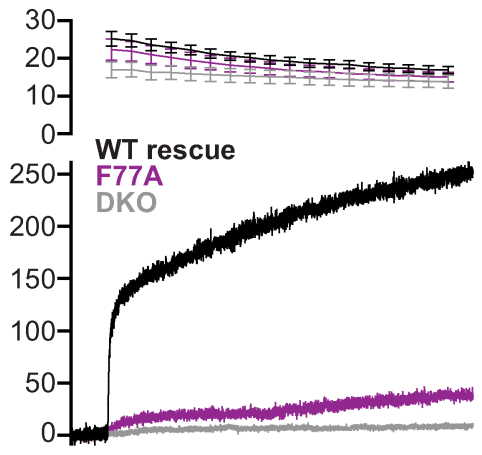

Figure 4. Mutations in layers 4 and 6 severely affect transmitter release. The mutations in layers 4 and 6 are shown in Fig. 1. (Ai and Bi) Mean secretory responses in $\mathrm{Ca}^{2+}$-triggered release are dramatically reduced in the L70A ( $\mathrm{Ai})$ and the F77A (Bi) mutant. For comparison, traces from double knockout cells (DKO) are included. Double knockout traces are pooled from an independent dataset and were not recorded in parallel to L7OA and F77A measurements. Mean \pm SEM of $\mathrm{Ca}^{2+}$ levels is shown. (Aii and Bii) Detailed view of normalized traces in $\mathrm{Ai}$ and $\mathrm{Bi}$. (A: WT rescue, $n=23$; L70A, $n=15$; double knockout, $n=21$; B: WT rescue, $n=8$; F77A, $n=13$; double knockout, $n=21$.)

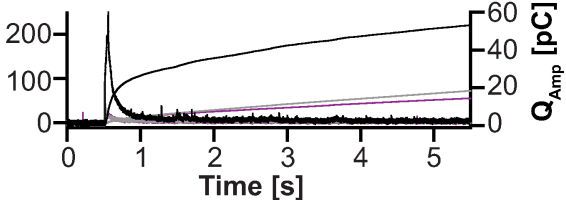

Bii

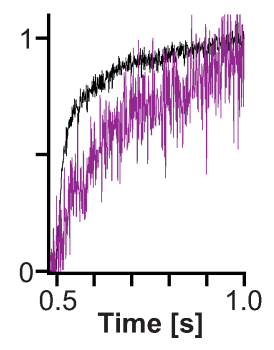

the SRP as well as the rate of the sustained component (the linear increase in the capacitance trace at times between 1.5 and $5.5 \mathrm{~s}$ ), which reflects the speed at which vesicles undergo functional maturation. However, the kinetics (time constants) for fusion from the RRP and the SRP were not significantly affected by $\mathrm{N}$-terminal destabilization, confirming that the $\mathrm{N}$-terminal part of the SNARE motif is important for vesicle priming but insignificant to the actual process of triggering release (refer to Table S1 for measured parameters of all mutants).

\section{C-terminal assembly}

To test how assembly of the C-terminal half of the SNARE complex is involved in vesicular release, we tested several mutants. Introducing point mutations layer by layer, we progressively moved from layer 4 toward the C-terminal end of the SNARE motif, again seeking to destabilize SNARE interaction by replacing endogenous residues with alanines. A single point mutation in layer 4, in which alanine was used to replace a leucine (L70A), had a dramatic effect on exocytosis (Fig. 4 Ai): the mutant led to only marginal rescue of secretion in double knockout cells in spite of being strongly overexpressed (Fig. S2). Strikingly, overexpression of the L70A construct in WT chromaffin cells was without effect on secretion (Fig. S3), suggesting that the mutation rendered the mutant protein incapable of competing with endogenous syb-2.

Layer 6 of the SNARE complex is special because in this layer, a bulky phenylalanine residue (F77) from syb-2 faces the small side chains of three alanines (two from SNAP-25 and one from syntaxin-1). This phenylalanine is found in almost all R-SNARE types (Kloepper et al., 2007), and thus, the extremely asymmetrical arrangement of layer 6 is conserved even in distantly related SNARE complexes such as the late endosomal complex (Antonin et al., 2002), indicating that it might be functionally important. Indeed, mutation of the phenylalanine to an alanine (F77A) almost eliminated secretion (Fig. $4 \mathrm{Bi}$ ). Yet, anisotropy measurements showed that the F77A mutant was able to displace the labeled $\mathrm{C}$-terminal synaptobrevin fragment from the $\Delta \mathrm{N}$ complex in vitro (Fig. S1 C). ITC measurements revealed a similar binding affinity as in the WT case (Table I), whereas the enthalpy was somewhat reduced. In conclusion, even though the region around layers 4 and 6 appears hypersensitive to mutation and essential for secretion, standard measurements in vitro do not identify problems in SNARE complex formation.

Mutating the most C-terminal layer 8 (leucine-84) to alanine (Fig. 1) resulted in a phenotype with robust rescue of secretion in response to $\mathrm{Ca}^{2+}$ uncaging (Fig. $5 \mathrm{Ai}$ ). However, detailed analysis of capacitance increase and cumulative amperometric current revealed a slowdown of the fast phase of neurotransmitter release (Fig. 5, Aii and Aiii). The specific nature of the residue used to replace the endogenous leucine was of minor importance because several different amino acids were studied, all of which showed a similar effect (Fig. 5 Bi). Even though mutants bearing an aspartate or a glycine in layer 8 also had an effect on the amplitude of the secretory response (Fig. $5 \mathrm{Bi}$ and Table S1), it is striking that their effect on release kinetics was very similar and, when looking at normalized traces, even indistinguishable (Fig. 5, Bii and Biii). Thus, destabilizing SNARE interaction in layer 8 predominantly reduced the speed at which vesicles underwent fusion, suggesting that the extreme C-terminal 
Figure 5. C-terminal mutants of syb-2 cause a slowdown of transmitter release. The C-terminal mutants of syb-2 are shown in Fig. 1. (Ai and Bi) Mean secretion in flash-evoked transmitter release is slowed down. (Aii and Bii) Detailed views of normalized traces in $\mathrm{Ai}$ and $\mathrm{Bi}$ show that the kinetics of release are slowed down in all cases. (Aiii and Biii) Time constants of the RRP and SRP obtained by fitting of exponentials show slowdown of release in the $L 84 \mathrm{~A}$ mutant (Aiii: control, $n=19$; and L84A, $n=$ $25)$ and $L 84 N$, L84G, and $L 84 D$ mutations (Biii: control, $n>15$; L84D, $n=9 / 14$; L84G $n=13 / 17$; and $L 84 \mathrm{~N}, n=15 / 19$ for RRP/ SRP time constants; and *, $\mathrm{P}<0.05$; $* *, \mathrm{P}<$ 0.01 ; and $* * *, P<0.001$ in $t$ test). (Ai, Aiii, $\mathrm{Bi}$, and $\mathrm{Biii)}$ Mean $\pm \mathrm{SEM}$ is shown.
$\mathrm{Ai}$

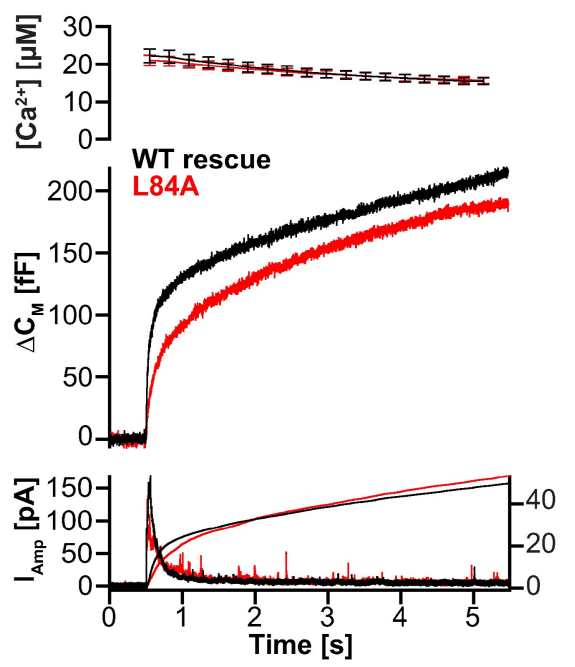

Aii

Aiii
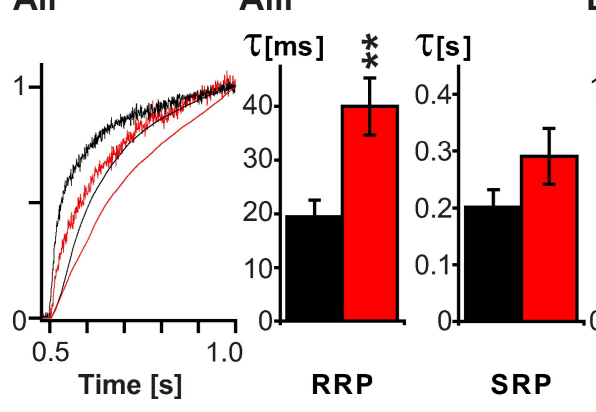

$\mathrm{Bi}$

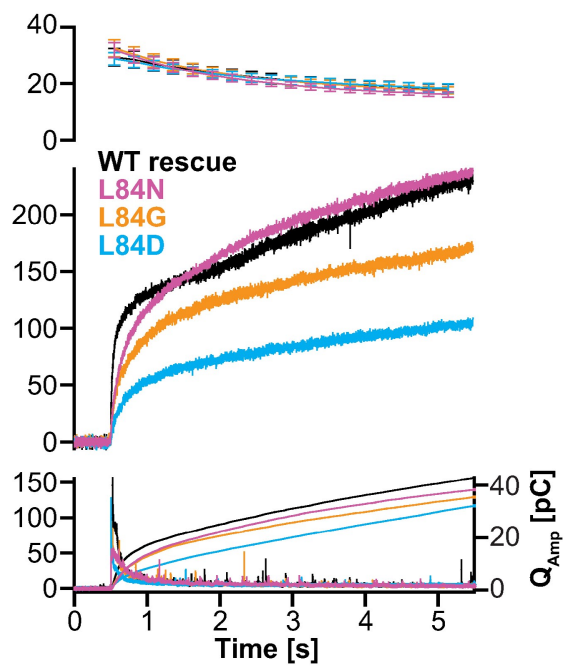

Bii
Biii

as peak amplitude, charge, rise time, or half-width (Fig. S4, $\mathrm{B}$ and $\mathrm{C}$ ) were unaltered. A reduction in foot duration implies a decreased lifetime of the fusion pore. A change in foot amplitude was not detected (Fig. S4, D and E). Note that this effect was reproducibly shown in two independent datasets, comparing control with L84A and VAVA mutants as well as comparing control with L84N and LATA mutants, respectively (Fig. 6, $\mathrm{A}$ and $\mathrm{B})$.

Wang et al. (2001) suggested the use of a simplified kinetic scheme analogous to the ones used to describe ion channel gating to analyze the fusion pore duration. In that scheme, opening of a fusion pore can be followed by either reversible closure, producing a stand-alone foot (SAF), or irreversible pore expansion, leading to full collapse (Fig. 6 C; Wang et al., 2006). Within this framework, a decreased lifetime of the fusion pore $\left(\tau_{0}\right)$ could be caused by an increased rate of expansion $\left(\mathrm{k}_{\mathrm{f}}\right)$, an increased rate of reclosure $\left(\mathrm{k}_{\mathrm{c}}\right)$, or both. These possibilities, in theory, can be distinguished by analyzing the fraction of SAFs, which should increase in the first case and decrease in the second case. Using two different criteria for the identification of SAFs, one based on a more rectangular shape expected for these events and one based on their lower amplitude, we did not detect any changes in the fraction of SAFs upon C-terminal mutation (Fig. S5). This indicates that either most events detected were not SAFs or that the changes seen were not caused by modification of a single transition rate in an otherwise unchanged kinetic scheme.

In conclusion, C-terminal mutation slowed triggered exocytosis and decreased the lifetime of the fusion pore. These 
$\mathbf{A i}$

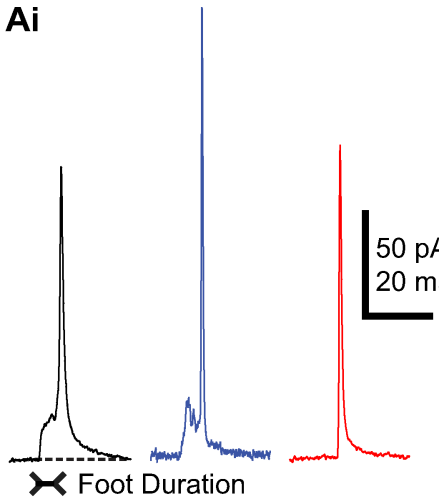

$\mathrm{Bi}$

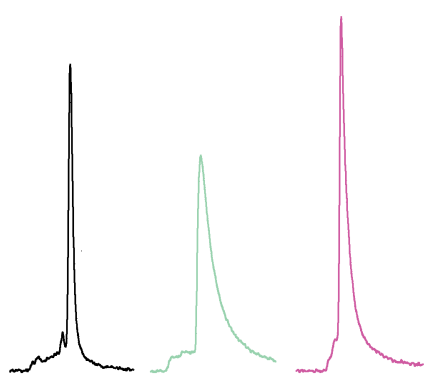

C
Aii

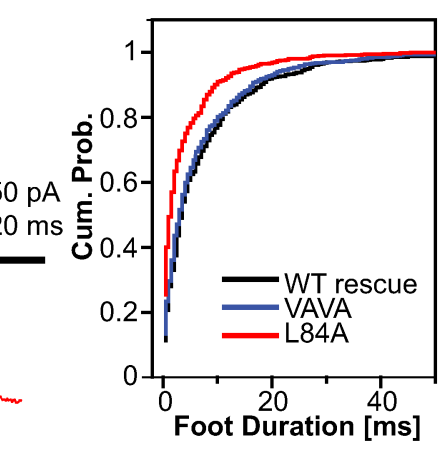

Bii

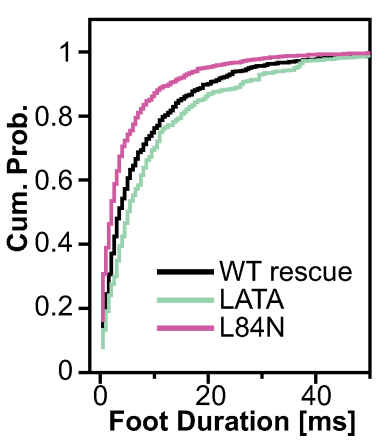

Aiii

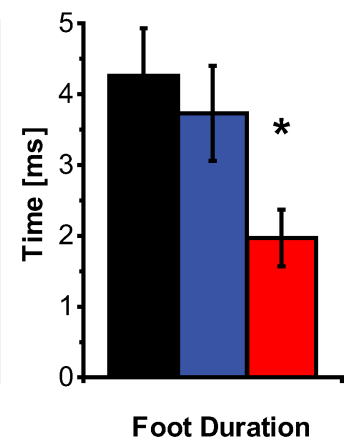

Biii

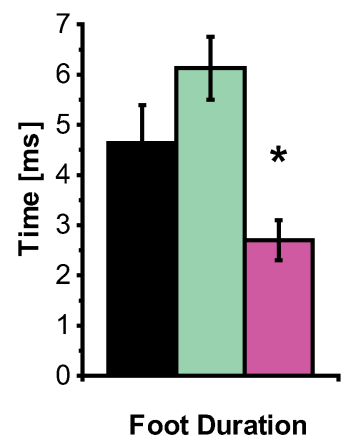

Figure 6. Fusion pore stability is affected by $\mathrm{C}$ - but not $\mathrm{N}$-terminal destabilization of the SNARE complex. (Ai and Bi) Examples of spikes recorded by means of carbon fiber amperometry. (Aii and Bii) Mean of cumulative probability (Cum. Prob.) distributions of the prespike foot duration shows a shift to shorter feet for C-terminal synaptobrevin mutants (L84A in Aii and $L 84 \mathrm{~N}$ in Bii). (Aiii and Biii) The mean foot duration (mean of cell medians) of C-terminal mutants is significantly reduced. Mean \pm SEM is shown (A: WT rescue, $n=16$ cells; VAVA, $n=19$ cells; and L84A, $n=19$ cells; and B: control, $n=14$ cells; LATA, $n=15$ cells; and L84N, $n=19$ cells; and *, $P<0.05$ in oneway ANOVA after log transformation yielded normally distributed homoscedastic data). (C) Proposed energy landscape for fusion (line), including barriers for vesicle priming, fusion triggering, and fusion pore expansion. The kinetic scheme comprises rate constants for pore formation $\left(k_{o}\right)$, pore closure $\left(k_{c}\right)$, and pore dilation $\left(\mathrm{k}_{\mathrm{f}}\right)$. In this model, the lifetime of the pore $\left(\tau_{0}\right)$ is defined by the inverse sum of the rate constants $k_{c}$ and $k_{f}$. The dashed line shows the proposed energy landscape after C-terminal mutation in syb-2. findings are consistent with a hypothesized energy landscape of the fusion reaction, in which C-terminal destabilization has two effects: to increase the fusion barrier and to destabilize the fusion pore intermediate (Fig. $6 \mathrm{C}$ ).

\section{Discussion}

The data presented in this study allow inferences about the events leading up to exocytosis of secretory vesicles. Destabilizing the SNARE bundle by N-terminal alanine substitution in syb-2 led to smaller primed vesicle pools and a shallower sustained phase, indicating that the forward priming rate under elevated $\mathrm{Ca}^{2+}$ conditions is reduced. This occurred in the absence of any detectable change in the triggering rate or fusion pore properties. The physiological changes correlated with a decreased association rate and affinity for the acceptor complex, as measured in vitro using biophysical methods, especially when the two N-terminal layers $(-7$ and -6$)$ were mutated (LATA). The VAVA mutation (located in layers -5 and -4 ) resulted in milder consequences in the in vitro situation, although the affinity for the $\Delta \mathrm{N}$ complex was reduced. In physiological measurements, both mutations had indistinguishable effects. The most likely reason for this discrepancy is that in vivo, additional catalyzing factors, possibly Munc18 (Deák et al., 2009) and/or CAPS $\left(\mathrm{Ca}^{2+}\right.$-dependent activator protein for secretion; James et al., 2009), cause synaptobrevin to associate with syntaxin-SNAP-25 in a slightly different sequence or over a longer stretch than in vitro. This interpretation was supported by biochemical experiments aimed at testing the effect of layers -5 and -4 (where the VAVA mutation is localized) in the absence of layers -6 and -7 (harboring the LATA mutation). This experiment (Fig. S1 B) showed a further reduction of association rate by the VAVA mutation compared with mutants merely bearing a deletion of layers -7 and $-6(\Delta 32-35$ VAVA and $\Delta 32-35$ in Fig. S1 B). Overall, our data indicate that assembly of the $\mathrm{N}$-terminal end of the ternary SNARE complex happens during vesicle priming, without being directly linked to downstream events involved in triggering release. The experiments presented 
in this study were necessary to draw this conclusion because previous mutations introduced in SNAP-25 (Sørensen et al., 2006) might have affected upstream processes, including the formation of the syntaxin-SNAP-25 acceptor complex involved in docking (de Wit et al., 2009). Only synaptobrevin mutations can clearly dissect the involvement of the ternary SNARE complex in exocytosis. The current data make a very strong case for the sequential two-step $\mathrm{N}$ - to $\mathrm{C}$-terminal assembly of the ternary SNARE complex. In contrast, our data are hard to reconcile with models in which the C-terminal end of synaptobrevin joins the complex first (Kweon et al., 2003).

As was the case for SNAP-25 (Xu et al., 1998; Wei et al., 2000; Sørensen et al., 2006), mutation in the C-most interaction layer, layer 8 in synaptobrevin, caused a slowdown of exocytosis triggering. This phenotype is relatively rare, demonstrating the robustness of the exocytosis machinery (Neher and Sakaba, 2008). The slowdown upon mutation indicates that assembly of this layer is coupled to $\mathrm{Ca}^{2+}$ binding to the $\mathrm{Ca}^{2+}$ sensor synaptotagmin, which times release with respect to the $\mathrm{Ca}^{2+}$ signal (Martens et al., 2007; for reviews see Chapman, 2008; Rizo and Rosenmund, 2008; Südhof and Rothman, 2009). The effect seems exclusive to the two to three most C-terminal interaction layers. It is of interest to note that both in vitro and in vivo studies have identified the last couple of C-terminal layers as more essential for release than the linker, which connects the SNARE complex to the transmembrane anchor of synaptobrevin (McNew et al., 1999; Melia et al., 2002; Kesavan et al., 2007; Siddiqui et al., 2007). Insertions in the linker of several amino acids only led to minor changes in release in chromaffin cells (Kesavan et al., 2007), whereas we show in this study that even rather conservative mutations in the last three SNARE layers suffice to abolish release. Thus, whereas C-terminal assembly is clearly essential for exocytosis, the exact structure of the linker region, which, according to current understanding, couples the released energy to the membrane, is less crucial.

Mutation of the C-most layer of synaptobrevin caused a reduction in duration of the prespike foot, reflecting a shorter lifetime of the fusion pore. Our analysis of small events, which might represent SAFs, did not reveal changes that would be consistent with an increased rate of fusion pore reclosure. Thus, it seems that the mutation has changed the energy landscape for fusion pore formation and dilation in a more complex way, such that the barrier for fusion triggering is higher (leading to slower time constants of fusion), whereas the barrier for fusion pore expansion is smaller (leading to a fusion pore with shorter life time; Fig. 6 C). The finding that mutations in the C-most interaction layer modified prespike feet implies that C-terminal SNARE complex assembly is involved in generating the fusion pore (Criado et al., 1999; Gil et al., 2002; Fang et al., 2008). However, whereas a previous publication reported an increased foot duration upon C-terminal mutation of SNAP-25 (Fang et al., 2008), we found in this study that the foot duration was decreased. This might be caused by the difference in protocol because in the previous study, using overexpression in bovine cells, vesicles might fuse using a mixture of WT (endogenous) and mutated protein. Another possibility is that there is a different role of syb-2 and SNAP-25 in fusion pore formation. This idea is supported by the finding of opposite effects (decrease and increase, respectively) on fusion pore duration after knockout of SNAP-25 (Sørensen et al., 2003) and syb-2 (Borisovska et al., 2005).

Our finding that more N-terminal mutants did not modify fusion pore duration seems to partially disagree with an overexpression study in PC12 cells (Han and Jackson, 2006). We cannot rule out the possibility that N-terminal mutations increase fusion pore duration in a way not detectable by our measurements because our use of cell-averaged statistics, which was necessary because of significant cell to cell variability (Colliver et al., 2000), results in less power than when spikes are combined across cells (Han and Jackson, 2006). In addition, differences in cell type or stimulation protocol might explain the differences. Of note is the fact that our mutation of layer 8 led to slower triggering rates and shorter fusion pore durations, features which have both been associated with a lack of syt-1-SNARE interaction (Bai et al., 2004; Voets et al., 2001a). Thus, the finding might be explained by postulating that C-terminal mutation decouples exocytosis from syt-1 action (Zhang et al., 2002).

Our mutations in layers 4 and 6 add to previous evidence that the transition zone between the $\mathrm{N}$-terminal three quarters and the C-terminal one quarter of the SNARE bundle is a critical area, as even relatively conservative mutations here are not tolerated (Nonet et al., 1998; Saifee et al., 1998; Sørensen et al., 2006). Because this area separates the priming from the triggering reaction, it might constitute a switch region, allowing rapid assembly of the C-terminal end. Notably, the L70A mutation in synaptobrevin that we studied here was not dominant when overexpressed in WT cells, whereas the previously isolated double alanine mutation in layer 5 of SNAP-25 eliminated release even in WT cells (Sørensen et al., 2006). With such data, the question of whether the protein is correctly localized becomes imminent. Immunolocalization indicated that the mutated protein is present in spots in the cytoplasm (Fig. S2), which probably corresponds to vesicles; however, the expression system (Semliki Forest virus) causes massive overexpression and results in large amounts of proteins in other locations of the cell. Even though this apparently does not compromise rescue of double knockout cells, it cannot be ruled out that mislocalized protein could interfere with function in the case of the L70A mutant. However, if taken at face value, our data on the L70A mutant could indicate that after assembly of the N-terminal end of the SNARE bundle, synaptobrevin can dissociate again if the switch associated with the C-terminal end of the complex is not functional. Indeed, assembly of the N-terminal part of synaptobrevin to syntaxin-SNAP-25 seems to be a reversible process until the C-terminal end joins (Wiederhold and Fasshauer, 2009). This might also explain the data obtained in this study (Fig. 5 B) and elsewhere (Kesavan et al., 2007) that show that more severe $\mathrm{C}$-terminal mutations tend to interfere with upstream steps in vesicle priming. The mechanism that prevents dissociation of syb-2 in the normal case might consist of complexin or syt-1 binding to the partly assembled SNARE complex, thereby stabilizing it while keeping the C-terminal end of synaptobrevin in a ready to go configuration. Failure of synaptotagmin binding would leave mutated synaptobrevin only loosely 
associated, eventually leading to its replacement by WT protein. The idea that synaptotagmin or complexin might bind to and stabilize the SNARE complex in a cocked configuration is consistent with the observation that the abundance of both complexin and synaptotagmin modify the size of the primed vesicle pools in chromaffin cells (Nagy et al., 2006; Cai et al., 2008).

Recent data obtained with a surface force apparatus indicated that assembly of the SNARE complex is associated with a binding energy of $\sim 35 \mathrm{k}_{\mathrm{B}} \mathrm{T}$ (Li et al., 2007), whereas ITC measurements gave a value close to $20 \mathrm{k}_{\mathrm{B}} \mathrm{T}$ (Wiederhold and Fasshauer, 2009). Both studies conclude that (a) assembly of the N-terminal three quarters of the SNARE bundle releases considerable energy and (b) assembly of the C-terminal one quarter releases much less energy, even though the latter conclusion could have been affected by the absence of a transmembrane domain in both studies. Together with our data, and for topological reasons, we would argue that the main part of the energy of formation of the complex goes into initiation and stabilization of the primed or cocked vesicle state but not into the triggering reaction itself. However, the primed vesicle has probably already overcome part of the energy barrier for fusion. The final triggering of release then coincides with the assembly of the C-terminal end of the complex. Even though this end might liberate less energy, the slowdown seen upon mutation argues for its contribution to the process. The main open question is how C-terminal SNARE complex "zippering" is prevented from occurring prematurely. Recent data indicate that complexin is involved in this process (Giraudo et al., 2006, 2009; Schaub et al., 2006; Huntwork and Littleton, 2007; Maximov et al., 2009), possibly by forming an alternative complex with the C-terminal end of the SNARE complex (Xue et al., 2007; Giraudo et al., 2009). However, because complexin mainly binds to synaptobrevin in the ternary SNARE complex (Chen et al., 2002) and therefore can only interact with the complex after it starts to assemble, it remains unclear how it can succeed in arresting fusion. We suggest that the transition zone around layers 4-6, possibly together with structural features recently identified in the SNAP-25 linker (Nagy et al., 2008), and the C-terminal weakness of the complex constitute endogenous properties, which prevent spontaneous assembly of the SNARE complex. These features allow time for complexin and/or synaptotagmin (for review see Südhof and Rothman, 2009) to interact and freeze the SNARE complex in a ready to go configuration.

\section{Materials and methods}

\section{Protein constructs and purification}

All recombinant proteins (syntaxin-1a, SNAP-25A, and syb-2) were derived from cDNAs from rat (Rattus norvegicus). All expression constructs were in the pET28a expression vector. As basic expression construct for the neuronal SNARE, we used the SNARE $(\mathrm{H} 3)$ domain of syntaxin-la (aa 180-262), the soluble portion of synaptobrevin (aa 1-96; Syb1-96), and a cysteine-free variant of SNAP-25A (aa 1-206; Fasshaver et al., 2002; Fasshaver and Margittai, 2004; Pobbati et al., 2006). In addition, various synaptobrevin mutants and truncations were used, and single cysteines were introduced at position 28 for labeling purposes: Sybl-96 L32A, T35A, S28C; Sybl-96 V39A, V42A, S28C; Sybl-96 L84A, S28C; Syb 1-96 L84N, S28C; Syb 1-96 $\Delta 32-35$, S28C; and Syb 1-96 $\Delta 32-35$, V39A, V42A, S28C. They were cloned into the pET28a vector (EMD) via Ndel and Xhol sites, resulting, after cleavage of the His6-tag by thrombin, in the additional $\mathrm{N}$-terminal sequence GSHM. All proteins were expressed in Escherichia coli strain BL21 (DE3) and purified by $\mathrm{Ni}^{2+}$ nitrilotriacetic acid chromatography followed by ion exchange chromatography on an Äkta system (GE Healthcare; Fasshaver et al., 1999). His6 tags were generally removed using thrombin. All SNARE complexes were purified using a Mono-Q column (GE Healthcare) after overnight assembly of the purified monomers. The following ternary complexes were used: Syb49-96:SyxH3:SNAP-25 ( $\Delta \mathrm{N}$ complex) and Syb1-96 C28 mutants: SyxH3:SNAP-25. Protein concentrations were determined by absorption at $280 \mathrm{~nm}$ in $6 \mathrm{M} \mathrm{GdnHCl}$ and/or using the Bradford assay.

ITC

ITC was performed on a VP-ITC instrument (MicroCal) at $25^{\circ} \mathrm{C}$. Samples were dialyzed twice against degassed phosphate buffer $(20 \mathrm{mM}$ Na phosphate, $\mathrm{pH} 7.4,150 \mathrm{mM} \mathrm{NaCl}$, and $1 \mathrm{mM} \mathrm{DTT}$ ). Typically, an initial 5-pl injection was followed by several 15-pl injections. The heat change per injection was integrated to yield the molar enthalpy for each injection. Blank titrations, which were performed by injecting ligand into buffer, were subtracted from each dataset. All ITC experiments were performed at least twice. The resulting binding isotherms were analyzed using the Origin ITC software packet (MicroCal) to obtain the binding enthalpy $(\Delta \mathrm{H})$, the stoichiometry $(\mathrm{N})$, and the association constant $\left(\mathrm{K}_{\mathrm{A}}\right)$. We used a one-site binding model that assumes that one or more ligands can bind independently. The dissociation constant $\left(K_{d}\right)$ and the binding free energy $(\Delta G)$ were calculated using the basic thermodynamic relationships $K_{d}=K_{A}^{-1}, \Delta G=-R T$ $\ln K_{A}$, and $\Delta G=\Delta \mathrm{H}-\mathrm{T} \Delta \mathrm{S}$.

\section{Fluorescence spectroscopy}

All measurements were performed in a Fluorolog 3 spectrometer in T configuration equipped for polarization (model FL322; HORIBA Jobin Yvon). In binding experiments, single cysteine variants of syb-2 were labeled with Alexa Fluor 488 C5 maleimide (Invitrogen) according to the manufacturer's instructions and added to the $\Delta \mathrm{N}$ complex. All experiments were performed at $25^{\circ} \mathrm{C}$ in $1-\mathrm{cm}$ quartz cuvettes (Hellma) in phosphate buffer $(20 \mathrm{mM}$ Na phosphate, $\mathrm{pH} 7.4,150 \mathrm{mM} \mathrm{NaCl}$, and $1 \mathrm{mM} \mathrm{DTT}$ ) using quartz cuvettes with a path length of $10 \times 4 \mathrm{~mm}$ (Hellma) equipped with a magnetic stirrer. Fluorescence anisotropy was measured. The anisotropy reports on the local flexibility of the labeled residue, which increases upon complex formation and decreases upon dissociation (Fasshaver and Margittai, 2004; Pobbati et al., 2006). In displacement experiments, the syb-2 fragment (Syb49-96) was labeled, and the decrease in anisotropy after its displacement by WT or mutated synaptobrevin was measured. The G factor was calculated according to $G=I_{\mathrm{HV}} / I_{\mathrm{HH}}$, where $I$ is the fluorescence intensity, the first subscript letter indicates the direction of the exciting light, and the second subscript letter indicates the direction of emitted light. The intensities of the vertically $(V)$ and horizontally $(H)$ polarized emission light after excitation by vertically polarized light were measured. The anisotropy (r) was determined according to $r=\left(I_{V V}-G I_{V H}\right) /\left(I_{V V}+2 G I_{V H}\right)$.

\section{CD spectroscopy}

CD measurements were performed using a Chirascan instrument (Applied Photophysics; Fasshauer et al., 2002). Hellma quartz cuvettes with a path length of $0.1 \mathrm{~cm}$ were used. The measurements were performed at $25^{\circ} \mathrm{C}$. For thermal denaturation experiments, the purified complexes were dialyzed against phosphate buffer. The ellipticity at $222 \mathrm{~nm}$ was recorded between 25 and $95^{\circ} \mathrm{C}$ at a temperature increment of $30^{\circ} \mathrm{C} / \mathrm{h}$.

\section{Adrenal chromaffin cell culture and expression of mutants}

The mouse strain was kept heterozygous for syb-2 and homozygous null for cellubrevin, and double knockouts were created by crossing heterozygous and recovered by Cesarean section on embryonic day 18. Embryonic adrenal glands were dissected out, placed in filtered Locke's solution $1154 \mathrm{mM}$ $\mathrm{NaCl}, 5.6 \mathrm{mM} \mathrm{KCl}, 0.85 \mathrm{mM} \mathrm{NaH}_{2} \mathrm{PO}_{4}, 2.15 \mathrm{mM} \mathrm{Na} \mathrm{HPO}_{4}$, and $10 \mathrm{mM}$ glucose, $\mathrm{pH} 7.01$, and cleaned free of connective tissue. The glands were incubated with $0.2 \mathrm{ml}$ of papain solution (see below) at $37^{\circ} \mathrm{C}$ for $40 \mathrm{~min}$ with slow shaking, followed by the addition of $150 \mu$ l of inactivating solution for $5 \mathrm{~min}$. The solution was then carefully replaced by $0.2 \mathrm{ml}$ enriched DME, and the glands were triturated gently through a $200-\mu l$ pipette tip. $50 \mu$ of the cell suspension was plated on each sterile coverslip in 6-well plates, and the cells were allowed to settle before supplementing with enriched medium. The cells were incubated at $37^{\circ} \mathrm{C}$ and $8 \% \mathrm{CO}_{2}$ and used within $3 \mathrm{~d}$. Papain solution: $250 \mathrm{ml}$ DME (Linaris) supplemented with $50 \mathrm{mg}$ L-cysteine, $2.5 \mathrm{ml}$ of $0.1 \mathrm{M} \mathrm{CaCl}_{2}, 2.5 \mathrm{ml}$ of $50 \mathrm{mM}$ EDTA, and 20-25 U/ml papain (Worthington Biochemical) and equilibrated with $5 \% \mathrm{CO}_{2}$. Inactivating solution: $225 \mathrm{ml} \mathrm{DME} \mathrm{supplemented} \mathrm{with} 25 \mathrm{ml}$ of heatinactivated fetal calf serum (Invitrogen), $625 \mathrm{mg}$ albumin, and $625 \mathrm{mg}$ trypsin inhibitor (Sigma-Aldrich). Enriched DME: $500 \mathrm{ml} \mathrm{DME} \mathrm{supplemented}$ 
with $2 \mathrm{ml}$ penicillin/streptomycin (Invitrogen) and $5 \mathrm{ml}$ insulin-transferrinselenium-X (Invitrogen).

Viral constructs containing a mouse syb-2 ORF followed by an internal ribosome entry site and EGFP were made in the pSFV1 plasmid, and Semliki Forest viruses were generated and used for the transfection of chromaffin cells as previously described (Ashery et al., 1999). Mutations were introduced into the PSFV1-based plasmid by PCR mutagenesis, and all constructs were verified by sequencing. After the addition of viruses to the cells, $4 \mathrm{~h}$ were allowed for expression of the protein. Control and mutant constructs were expressed in cells from the same preparations of syb-2/cellubrevin double knockout mice to cancel variability between preparations.

\section{Exocytosis measurements}

Conventional whole cell patch-clamp recordings were performed at room temperature with Sylgard-coated 3-5-M $\Omega$ pipettes (Kimax-51; Kimble Chase). An EPC-9 patch-clamp amplifier was used together with the Pulse software package (HEKA). Capacitance measurements were performed by using the Lindau-Neher technique implemented as the "sine $+\mathrm{dc}^{\text {" mode of }}$ the software lock-in extension of Pulse, which allows long-duration capacitance measurements in a single sweep. A 1,000-Hz, 70-mV peak to peak sinusoid voltage stimulus was superimposed onto a $\mathrm{DC}$ holding potential of $-70 \mathrm{mV}$. Currents were filtered at $3 \mathrm{kHz}$ and sampled at $12 \mathrm{kHz}$.

The external solution contained $145 \mathrm{mM} \mathrm{NaCl}, 2.8 \mathrm{mM} \mathrm{KCl}, 2 \mathrm{mM}$ $\mathrm{CaCl}_{2}, 1 \mathrm{mM} \mathrm{MgCl}$, and $10 \mathrm{mM}$ Hepes plus $2 \mathrm{mg} / \mathrm{ml}$ D-glucose, $\mathrm{pH} 7.2$ (osmolarity was adjusted to $310 \mathrm{mOsM}$ ). The pipette solution contained $100 \mathrm{mM}$ Cs-glutamate, $8 \mathrm{mM} \mathrm{NaCl}, 4 \mathrm{mM} \mathrm{CaCl}$, $32 \mathrm{mM}$ Hepes, $2 \mathrm{mM}$ Mg-ATP, $0.3 \mathrm{mM}$ GTP, $1 \mathrm{mM}$ ascorbic acid, $5 \mathrm{mM}$ nitrophenyl-EGTA (Invitrogen), $0.4 \mathrm{mM}$ fura-4F (Invitrogen), and $0.4 \mathrm{mM}$ furaptra (Invitrogen), $\mathrm{pH} 7.2$ (osmolarity was adjusted to $300 \mathrm{mOsM}$ ). Compared with previous experiments (Voets, 2000; Sørensen et al., 2006), the intracellular solution was modified by the addition of ascorbic acid, which protects against photodamage of the fura dyes upon uncaging with UV light. This allows a simplification of the $\mathrm{Ca}^{2+}$ calibration because posfflash calibration (Heinemann et al., 1994) becomes unnecessary.

Flashes of UV light were generated by a flash lamp (Rapp Optoelektronik), and fluorescence excitation light was generated by a monochromator (TILL Photonics); these were coupled into the epifluorescence port of an inverted microscope (Axiovert 100; Carl Zeiss, Inc.) with a 40x Fluar objective (Carl Zeiss, Inc.). The fluorescent dyes were excited at 350/380 nm, and the illumination area was reduced to cover only the diameter of the cell. Emitted light was detected with a photomultiplier, filtered at $3 \mathrm{kHz}$, and sampled at $12 \mathrm{kHz}$ by Pulse software. The fluorescence ratio signal was calibrated in separate experiments by infusing the cell with solutions with known $\left[\mathrm{Ca}^{2+}\right]_{i}$ buffered by $20 \mathrm{mM}$ BAPTA (Invitrogen) or 1,3-Diamino2-hydroxy-propane-N,N, $N^{\prime}, N^{\prime}$-tetraacetic acid (DPTA; Sigma-Aldrich). The $\left[\mathrm{Ca}^{2+}\right]_{i}$ was calculated using a $K_{\mathrm{d}}$ of $0.222 \mu \mathrm{M}$ for BAPTA and $80 \mu \mathrm{M}$ for DPTA while taking into account $\mathrm{Ca}^{2+}$ binding to the dyes, nitrophenyl-EGTA and ATP, using a custom-written macro running in lgorPro (WaveMetrics). Fluorescent excitation light was used not only to measure $\left[\mathrm{Ca}^{2+}\right]_{i}$ but also to adjust $\left[\mathrm{Ca}^{2+}\right]_{i}$ by inducing gradual photolysis of the $\mathrm{Ca}^{2+}$ cage before the flash, such that cells could be studied under conditions of uniform preflash $\left[\mathrm{Ca}^{2+}\right]_{i}($ Voets, 2000).

Capacitance, $\mathrm{Ca}^{2+}$, and amperometric traces were imported to lgorPro for analysis. The displayed $\mathrm{Ca}^{2+}$ concentrations, capacitance traces, and amperometric currents were averaged over all cells recorded for each condition. Pool sizes and fusion time constants were obtained by fitting a sum of exponential functions to individual capacitance traces (Sørensen et al., 2003). The function fitted contained two exponential components for the exocytotic burst component, which have previously been associated with two different vesicles pools: the RRP and the SRP, respectively (Voets et al., 1999; Voets, 2000). The sizes of these pools were taken from the amplitude of the corresponding exponential component, and the time constant was reported as a measure of fusion speed. The exocytotic burst (fusion of RRP and SRP) took place within the first second after a step increase in the $\mathrm{Ca}^{2+}$ concentration. The near-linear sustained component, which followed, was calculated by taking the value of the capacitance trace $5 \mathrm{~s}$ after photorelease of $\mathrm{Ca}^{2+}$ and subtracting the value after $1 \mathrm{~s}$. The result was given as capacitance increase per second.

Data are represented as mean \pm SEM, with $n$ denoting the number of cells. Statistical analysis was performed using $t$ tests on homoscedastic data and assessed by Levene's test of equality of variance. Where necessary, heteroscedastic data were log-transformed to yield homoscedastic data before testing.

Data for amperometric spike analysis were obtained in two independent experimental datasets, each comparing an $\mathrm{N}$ - and C-terminal mutant with WT protein in cells from double knockout mice. Carbon fibers were $5 \mu \mathrm{m}$ in diameter (BP Amoco Chemical Co.), insulated by electropaint deposition (Schulte and Chow, 1996), frequently cut between recordings, and systematically switched between all conditions tested. The fibers were gently pressed against the cell during recording. Fibers were clamped to $720 \mathrm{mV}$, and currents were filtered at $3 \mathrm{kHz}$ by an EPC-7 (HEKA). Currents were acquired at $12 \mathrm{kHz}$ and filtered off-line using a Gaussian filter with a cut-off set at $1 \mathrm{kHz}$. Filtering, spike detection, and analysis were performed using a custom-written macro running under IgorPro. Statistics were performed using the mean of cell medians of each parameter because amperometric parameters generally display very large cell to cell variability. Significance levels were assayed by analysis of variance (ANOVA). The effect of recording sequence, animal preparations, and different fibers were tested by ANOVA but were all nonsignificant factors.

\section{Immunostaining and imaging}

Chromaffin cells were cultured on poly-l-lysine-coated coverslips, fixed in $3.7 \%$ PFA in PBS for 20 min, washed, and permeabilized in $0.2 \%$ Triton $\mathrm{X}-100$. Remaining PFA was neutralized in $50 \mathrm{mM} \mathrm{NH}_{4} \mathrm{Cl}$. Cells were blocked in $2 \%$ bovine albumin serum (Sigma-Aldrich) and incubated with primary antibodies (1:500 mouse anti-syb-2 and 1:200 rabbit anti-syt-1; both provided by R. Jahn, Max Planck Institute for Biophysical Chemistry, Göttingen, Germany) for $2 \mathrm{~h}$. Cells were washed four times, incubated with secondary antibodies 1:200 Alexa Fluor 546-conjugated goat anti-mouse and 1:200 Alexa Fluor 647-conjugated goat anti-rabbit), washed, and mounted for imaging. Fluorescence quantification was performed in PBS at room temperature on a microscope (Axiovert 200; Carl Zeiss, Inc.) equipped with a $63 \times$ NA 1.2 C-Apochromat water-immersion objective. Fluorescence excitation was achieved by monochromatic light (Polychrome V; TILL Photonics). Images were acquired by a camera (Sensicam; PCO Imaging) and analyzed using TILLvisION (version 4.0.1; TILL Photonics). Fluorescence levels were quantified as the integrated intensity of a square region of the image containing the cell minus the intensity of a background region of the same size. Data were averaged over cells and are represented as mean and SEM. Confocal imaging was performed in PBS at room temperature on a microscope (TCS SP5; Leica) with an HCX PlanApochromat lambda blue $63 \times$ NA 1.4 oil UV objective. Image processing was used using LAS AF software (version 1.7.0 build 1111; Leica).

\section{Online supplemental material}

Fig. S1 shows that synaptobrevin mutants form stable complexes and that fast assembly requires interaction of the first four $\mathrm{N}$-terminal layers. Fig. S2 shows localization and expression levels of all mutants tested by quantitative immunostaining. Fig. S3 shows that overexpression of the L70A mutant in WT (control) chromaffin cells does not change secretion. Fig. S4 shows cumulative probability plots for all measured single spike parameters for the dataset displayed in Fig. 6 in addition to foot amplitudes as a function of imposing a duration threshold. Fig. S5 is an attempt to detect SAFs in embryonic mouse chromaffin cells using two different criteria. Online supplemental material is available at http://www.jcb .org/cgi/content/full/jcb.200907018/DC1.

We are grateful to Dirk Reuter and Ina Herfort for expert technical assistance. We thank Erwin Neher for support and advice on the manuscript. In addition, we thank Manfred Lindau for commenting on the manuscript.

This work has been supported by the Deutsche Forschungsgemeinschaft Igrant SFB523-B16 to J.B. Sørensen and grant SFB523-B1 1 to D. Fasshaver) and by a Junior Group Leader Fellowship from the Lundbeck Foundation (to J.B. Sørensen). A.M. Walter was a PhD student of the International MD-PhD/PhD Program in the Neurosciences of the International Max Planck Research School.

Submitted: 3 July 2009

Accepted: 7 January 2010

\section{References}

An, S.J., and W. Almers. 2004. Tracking SNARE complex formation in live endocrine cells. Science. 306:1042-1046. doi:10.1126/science.1102559

Antonin, W., D. Fasshauer, S. Becker, R. Jahn, and T.R. Schneider. 2002. Crystal structure of the endosomal SNARE complex reveals common structural principles of all SNAREs. Nat. Struct. Biol. 9:107-111. doi:10.1038/nsb746

Ashery, U., A. Betz, T. Xu, N. Brose, and J. Rettig. 1999. An efficient method for infection of adrenal chromaffin cells using the Semliki Forest virus gene expression system. Eur. J. Cell Biol. 78:525-532. 
Bai, J., C.T. Wang, D.A. Richards, M.B. Jackson, and E.R. Chapman. 2004 Fusion pore dynamics are regulated by synaptotagmin*t-SNARE interactions. Neuron. 41:929-942. doi:10.1016/S0896-6273(04)00117-5

Baumert, M., P.R. Maycox, F. Navone, P. De Camilli, and R. Jahn. 1989. Synaptobrevin: an integral membrane protein of 18,000 daltons present in small synaptic vesicles of rat brain. EMBO J. 8:379-384.

Bennett, M.K., N. Calakos, and R.H. Scheller. 1992. Syntaxin: a synaptic protein implicated in docking of synaptic vesicles at presynaptic active zones. Science. 257:255-259. doi:10.1126/science.1321498

Bhalla, A., M.C. Chicka, W.C. Tucker, and E.R. Chapman. 2006. Ca(2+)-synaptotagmin directly regulates t-SNARE function during reconstituted membrane fusion. Nat. Struct. Mol. Biol. 13:323-330. doi:10.1038/nsmb1076

Borisovska, M., Y. Zhao, Y. Tsytsyura, N. Glyvuk, S. Takamori, U. Matti, J. Rettig, T. Südhof, and D. Bruns. 2005. v-SNAREs control exocytosis of vesicles from priming to fusion. EMBO J. 24:2114-2126. doi:10.1038/sj.emboj.7600696

Broadie, K., A. Prokop, H.J. Bellen, C.J. O'Kane, K.L. Schulze, and S.T. Sweeney. 1995. Syntaxin and synaptobrevin function downstream of vesicle docking in Drosophila. Neuron. 15:663-673. doi:10.1016/ 0896-6273(95)90154-X

Cai, H., K. Reim, F. Varoqueaux, S. Tapechum, K. Hill, J.B. Sørensen, N. Brose, and R.H. Chow. 2008. Complexin II plays a positive role in Ca2+-triggered exocytosis by facilitating vesicle priming. Proc. Natl. Acad. Sci. USA. 105:19538-19543. doi:10.1073/pnas.0810232105

Chapman, E.R. 2008. How does synaptotagmin trigger neurotransmitter release? Аnnu. Rev. Biochem. 77:615-641. doi:10.1146/annurev .biochem.77.062005.101135

Chen, X., D.R. Tomchick, E. Kovrigin, D. Araç, M. Machius, T.C. Südhof, and J. Rizo. 2002. Three-dimensional structure of the complexin/SNARE complex. Neuron. 33:397-409. doi:10.1016/S0896-6273(02)00583-4

Chicka, M.C., E. Hui, H. Liu, and E.R. Chapman. 2008. Synaptotagmin arrests the SNARE complex before triggering fast, efficient membrane fusion in response to Ca2+. Nat. Struct. Mol. Biol. 15:827-835. doi: $10.1038 /$ nsmb. 1463

Chow, R.H., L. von Rüden, and E. Neher. 1992. Delay in vesicle fusion revealed by electrochemical monitoring of single secretory events in adrenal chromaffin cells. Nature. 356:60-63. doi:10.1038/356060a0

Colliver, T.L., E.J. Hess, E.N. Pothos, D. Sulzer, and A.G. Ewing. 2000. Quantitative and statistical analysis of the shape of amperometric spikes recorded from two populations of cells. J. Neurochem. 74:1086-1097.

Criado, M., A. Gil, S. Viniegra, and L.M. Gutiérrez. 1999. A single amino acid near the $\mathrm{C}$ terminus of the synaptosomeassociated protein of $25 \mathrm{kDa}$ (SNAP-25) is essential for exocytosis in chromaffin cells. Proc. Natl. Acad. Sci. USA. 96:7256-7261. doi:10.1073/pnas.96.13.7256

Dai, H., N. Shen, D. Araç, and J. Rizo. 2007. A quaternary SNARE-synaptotagmin-Ca2+-phospholipid complex in neurotransmitter release. J. Mol. Biol. 367:848-863. doi:10.1016/j.jmb.2007.01.040

de Wit, H., L.N. Cornelisse, R.F. Toonen, and M. Verhage. 2006. Docking of secretory vesicles is syntaxin dependent. PLoS One. 1:e126. doi:10.1371/ journal.pone. 0000126

de Wit, H., A.M. Walter, I. Milosevic, A. Gulyás-Kovács, D. Riedel, J.B. Sørensen, and M. Verhage. 2009. Synaptotagmin-1 docks secretory vesicles to syntaxin-1/SNAP-25 acceptor complexes. Cell. 138:935-946. doi:10.1016/j.cell.2009.07.027

Deák, F., Y. Xu, W.P. Chang, I. Dulubova, M. Khvotchev, X. Liu, T.C. Südhof, and J. Rizo. 2009. Munc18-1 binding to the neuronal SNARE complex controls synaptic vesicle priming. J. Cell Biol. 184:751-764. doi:10.1083/jcb.200812026

Dulubova, I., S. Sugita, S. Hill, M. Hosaka, I. Fernandez, T.C. Südhof, and J. Rizo. 1999. A conformational switch in syntaxin during exocytosis: role of munc18. EMBO J. 18:4372-4382. doi:10.1093/emboj/18.16.4372

Elferink, L.A., W.S. Trimble, and R.H. Scheller. 1989. Two vesicle-associated membrane protein genes are differentially expressed in the rat central nervous system. J. Biol. Chem. 264:11061-11064.

Fang, Q., K. Berberian, L.W. Gong, I. Hafez, J.B. Sørensen, and M. Lindau. 2008. The role of the $\mathrm{C}$ terminus of the SNARE protein SNAP-25 in fusion pore opening and a model for fusion pore mechanics. Proc. Natl. Acad. Sci. USA. 105:15388-15392. doi:10.1073/pnas.0805377105

Fasshauer, D., and M. Margittai. 2004. A transient N-terminal interaction of SNAP-25 and syntaxin nucleates SNARE assembly. J. Biol. Chem. 279:7613-7621. doi:10.1074/jbc.M312064200

Fasshauer, D., H. Otto, W.K. Eliason, R. Jahn, and A.T. Brünger. 1997. Structural changes are associated with soluble $\mathrm{N}$-ethylmaleimide-sensitive fusion protein attachment protein receptor complex formation. J. Biol. Chem. 272:28036-28041. doi:10.1074/jbc.272.44.28036

Fasshauer, D., R.B. Sutton, A.T. Brunger, and R. Jahn. 1998. Conserved structural features of the synaptic fusion complex: SNARE proteins reclassified as Q- and R-SNAREs. Proc. Natl. Acad. Sci. USA. 95:15781-15786. doi:10.1073/pnas.95.26.15781

Fasshauer, D., W. Antonin, M. Margittai, S. Pabst, and R. Jahn. 1999. Mixed and non-cognate SNARE complexes. Characterization of assembly and biophysical properties. J. Biol. Chem. 274:15440-15446. doi:10.1074/jbc.274.22.15440

Fasshauer, D., W. Antonin, V. Subramaniam, and R. Jahn. 2002. SNARE assembly and disassembly exhibit a pronounced hysteresis. Nat. Struct. Biol. 9:144-151. doi:10.1038/nsb750

Gerber, S.H., J.C. Rah, S.W. Min, X. Liu, H. de Wit, I. Dulubova, A.C. Meyer, J. Rizo, M. Arancillo, R.E. Hammer, et al. 2008. Conformational switch of syntaxin-1 controls synaptic vesicle fusion. Science. 321:1507-1510. doi:10.1126/science.1163174

Gil, A., L.M. Gutiérrez, C. Carrasco-Serrano, M.T. Alonso, S. Viniegra, and M. Criado. 2002. Modifications in the C terminus of the synaptosomeassociated protein of $25 \mathrm{kDa}$ (SNAP-25) and in the complementary region of synaptobrevin affect the final steps of exocytosis. J. Biol. Chem. 277:9904-9910. doi:10.1074/jbc.M110182200

Giraudo, C.G., W.S. Eng, T.J. Melia, and J.E. Rothman. 2006. A clamping mechanism involved in SNARE-dependent exocytosis. Science. 313:676-680. doi:10.1126/science. 1129450

Giraudo, C.G., A. Garcia-Diaz, W.S. Eng, Y. Chen, W.A. Hendrickson, T.J. Melia, and J.E. Rothman. 2009. Alternative zippering as an on-off switch for SNARE-mediated fusion. Science. 323:512-516. doi:10.1126/ science. 1166500

Guan, R., H. Dai, and J. Rizo. 2008. Binding of the Munc13-1 MUN domain to membrane-anchored SNARE complexes. Biochemistry. 47:1474-1481. doi:10.1021/bi702345m

Gulyás-Kovács, A., H. de Wit, I. Milosevic, O. Kochubey, R. Toonen, J. Klingauf, M. Verhage, and J.B. Sørensen. 2007. Munc18-1: sequential interactions with the fusion machinery stimulate vesicle docking and priming. J. Neurosci. 27:8676-8686. doi:10.1523/JNEUROSCI.0658-07.2007

Halemani, N.D., I. Bethani, S.O. Rizzoli, and T. Lang. 2009. Structure and dynamics of a two-helix SNARE complex in live cells. Traffic. doi:10.1111/ j.1600-0854.2009.01020.x.

Hammarlund, M., M.T. Palfreyman, S. Watanabe, S. Olsen, and E.M. Jorgensen. 2007. Open syntaxin docks synaptic vesicles. PLoS Biol. 5:e198. doi:10.1371/journal.pbio.0050198

Han, X., and M.B. Jackson. 2006. Structural transitions in the synaptic SNARE complex during $\mathrm{Ca}^{2+}$-triggered exocytosis. J. Cell Biol. 172:281-293. doi:10.1083/jcb.200510012

Hanson, P.I., J.E. Heuser, and R. Jahn. 1997a. Neurotransmitter release four years of SNARE complexes. Curr. Opin. Neurobiol. 7:310-315. doi:10.1016/S0959-4388(97)80057-8

Hanson, P.I., R. Roth, H. Morisaki, R. Jahn, and J.E. Heuser. 1997b. Structure and conformational changes in NSF and its membrane receptor complexes visualized by quick-freeze/deep-etch electron microscopy. Cell. 90:523-535. doi:10.1016/S0092-8674(00)80512-7

Hayashi, T., H. McMahon, S. Yamasaki, T. Binz, Y. Hata, T.C. Südhof, and H. Niemann. 1994. Synaptic vesicle membrane fusion complex: action of clostridial neurotoxins on assembly. EMBO J. 13:5051-5061.

Heinemann, C., R.H. Chow, E. Neher, and R.S. Zucker. 1994. Kinetics of the secretory response in bovine chromaffin cells following flash photolysis of caged Ca2+. Biophys. J. 67:2546-2557. doi:10.1016/ S0006-3495(94)80744-1

Huntwork, S., and J.T. Littleton. 2007. A complexin fusion clamp regulates spontaneous neurotransmitter release and synaptic growth. Nat. Neurosci. 10:1235-1237. doi:10.1038/nn1980

Jahn, R., and R.H. Scheller. 2006. SNAREs—engines for membrane fusion. Nat. Rev. Mol. Cell Biol. 7:631-643. doi:10.1038/nrm2002

James, D.J., J. Kowalchyk, N. Daily, M. Petrie, and T.F. Martin. 2009. CAPS drives trans-SNARE complex formation and membrane fusion through syntaxin interactions. Proc. Natl. Acad. Sci. USA. 106:17308-17313. doi:10.1073/pnas.0900755106

Kesavan, J., M. Borisovska, and D. Bruns. 2007. v-SNARE actions during $\mathrm{Ca}(2+)$-triggered exocytosis. Cell. 131:351-363. doi:10.1016/j.cell 2007.09.025

Kloepper, T.H., C.N. Kienle, and D. Fasshauer. 2007. An elaborate classification of SNARE proteins sheds light on the conservation of the eukaryotic endomembrane system. Mol. Biol. Cell. 18:3463-3471. doi:10.1091/ mbc.E07-03-0193

Kweon, D.H., C.S. Kim, and Y.K. Shin. 2003. Insertion of the membrane-proximal region of the neuronal SNARE coiled coil into the membrane. J. Biol. Chem. 278:12367-12373. doi:10.1074/jbc.M211123200

Li, C., B. Ullrich, J.Z. Zhang, R.G. Anderson, N. Brose, and T.C. Südhof. 1995. $\mathrm{Ca}(2+)$-dependent and -independent activities of neural and non-neural synaptotagmins. Nature. 375:594-599. doi:10.1038/375594a0 
Li, F., F. Pincet, E. Perez, W.S. Eng, T.J. Melia, J.E. Rothman, and D. Tareste. 2007. Energetics and dynamics of SNAREpin folding across lipid bilayers. Nat. Struct. Mol. Biol. 14:890-896. doi:10.1038/nsmb1310

Lindau, M., and E. Neher. 1988. Patch-clamp techniques for time-resolved capacitance measurements in single cells. Pflugers Arch. 411:137-146. doi:10.1007/BF00582306

Malsam, J., S. Kreye, and T.H. Söllner. 2008. Membrane fusion: SNAREs and regulation. Cell. Mol. Life Sci. 65:2814-2832. doi:10.1007/s00018-008-8352-3

Margittai, M., D. Fasshauer, R. Jahn, and R. Langen. 2003. The Habc domain and the SNARE core complex are connected by a highly flexible linker. Biochemistry. 42:4009-4014. doi:10.1021/bi027437z

Martens, S., M.M. Kozlov, and H.T. McMahon. 2007. How synaptotagmin promotes membrane fusion. Science. 316:1205-1208. doi:10.1126/ science. 1142614

Maximov, A., J. Tang, X. Yang, Z.P. Pang, and T.C. Südhof. 2009. Complexin controls the force transfer from SNARE complexes to membranes in fusion. Science. 323:516-521. doi:10.1126/science.1166505

McNew, J.A., T. Weber, D.M. Engelman, T.H. Söllner, and J.E. Rothman. 1999. The length of the flexible SNAREpin juxtamembrane region is a critical determinant of SNARE-dependent fusion. Mol. Cell. 4:415-421. doi:10.1016/S1097-2765(00)80343-3

Melia, T.J., T. Weber, J.A. McNew, L.E. Fisher, R.J. Johnston, F. Parlati, L.K. Mahal, T.H. Sollner, and J.E. Rothman. 2002. Regulation of membrane fusion by the membrane-proximal coil of the t-SNARE during zippering of SNAREpins. J. Cell Biol. 158:929-940. doi:10.1083/ jcb.200112081

Nagy, G., J.H. Kim, Z.P. Pang, U. Matti, J. Rettig, T.C. Südhof, and J.B. Sørensen. 2006. Different effects on fast exocytosis induced by synaptotagmin 1 and 2 isoforms and abundance but not by phosphorylation. J. Neurosci. 26:632-643. doi:10.1523/JNEUROSCI.2589-05.2006

Nagy, G., I. Milosevic, R. Mohrmann, K. Wiederhold, A.M. Walter, and J.B. Sørensen. 2008. The SNAP-25 linker as an adaptation toward fast exocytosis. Mol. Biol. Cell. 19:3769-3781. doi:10.1091/mbc.E07-12-1218

Neher, E. 2006. A comparison between exocytic control mechanisms in adrenal chromaffin cells and a glutamatergic synapse. Pflugers Arch. 453:261268. doi:10.1007/s00424-006-0143-9

Neher, E., and T. Sakaba. 2008. Multiple roles of calcium ions in the regulation of neurotransmitter release. Neuron. 59:861-872. doi:10.1016/ j.neuron.2008.08.019

Nonet, M.L., O. Saifee, H. Zhao, J.B. Rand, and L. Wei. 1998. Synaptic transmission deficits in Caenorhabditis elegans synaptobrevin mutants. J. Neurosci. 18:70-80.

Oyler, G.A., G.A. Higgins, R.A. Hart, E. Battenberg, M. Billingsley, F.E. Bloom, and M.C. Wilson. 1989. The identification of a novel synaptosomal-associated protein, SNAP-25, differentially expressed by neuronal subpopulations. J. Cell Biol. 109:3039-3052. doi:10.1083/jcb.109.6.3039

Pobbati, A.V., A. Stein, and D. Fasshauer. 2006. N- to C-terminal SNARE complex assembly promotes rapid membrane fusion. Science. 313:673-676. doi:10.1126/science.1129486

Rickman, C., and B. Davletov. 2003. Mechanism of calcium-independent synaptotagmin binding to target SNAREs. J. Biol. Chem. 278:55015504. doi:10.1074/jbc.C200692200

Rickman, C., F.A. Meunier, T. Binz, and B. Davletov. 2004. High affinity interaction of syntaxin and SNAP-25 on the plasma membrane is abolished by botulinum toxin E. J. Biol. Chem. 279:644-651. doi:10.1074/jbc .M310879200

Rizo, J., and C. Rosenmund. 2008. Synaptic vesicle fusion. Nat. Struct. Mol. Biol. 15:665-674. doi:10.1038/nsmb.1450

Saifee, O., L. Wei, and M.L. Nonet. 1998. The Caenorhabditis elegans unc-64 locus encodes a syntaxin that interacts genetically with synaptobrevin. Mol. Biol. Cell. 9:1235-1252.

Schaub, J.R., X. Lu, B. Doneske, Y.K. Shin, and J.A. McNew. 2006. Hemifusion arrest by complexin is relieved by Ca2+-synaptotagmin I. Nat. Struct. Mol. Biol. 13:748-750. doi:10.1038/nsmb1124

Schiavo, G., G. Stenbeck, J.E. Rothman, and T.H. Söllner. 1997. Binding of the synaptic vesicle v-SNARE, synaptotagmin, to the plasma membrane t-SNARE, SNAP-25, can explain docked vesicles at neurotoxintreated synapses. Proc. Natl. Acad. Sci. USA. 94:997-1001. doi:10.1073/ pnas.94.3.997

Schoch, S., F. Deák, A. Königstorfer, M. Mozhayeva, Y. Sara, T.C. Südhof, and E.T. Kavalali. 2001. SNARE function analyzed in synaptobrevin/ VAMP knockout mice. Science. 294:1117-1122. doi:10.1126/science .1064335

Schuette, C.G., K. Hatsuzawa, M. Margittai, A. Stein, D. Riedel, P. Küster, M. König, C. Seidel, and R. Jahn. 2004. Determinants of liposome fusion mediated by synaptic SNARE proteins. Proc. Natl. Acad. Sci. USA. 101:2858-2863. doi:10.1073/pnas.0400044101
Schulte, A., and R.H. Chow. 1996. A simple method for insulating carbon-fiber microelectrodes using anodic electrophoretic deposition of paint. Anal. Chem. 68:3054-3058. doi:10.1021/ac960210n

Siddiqui, T.J., O. Vites, A. Stein, R. Heintzmann, R. Jahn, and D. Fasshauer 2007. Determinants of synaptobrevin regulation in membranes. Mol. Biol. Cell. 18:2037-2046. doi:10.1091/mbc.E07-01-0049

Söllner, T., M.K. Bennett, S.W. Whiteheart, R.H. Scheller, and J.E. Rothman. 1993. A protein assembly-disassembly pathway in vitro that may correspond to sequential steps of synaptic vesicle docking, activation, and fusion. Cell. 75:409-418. doi:10.1016/0092-8674(93)90376-2

Sørensen, J.B., G. Nagy, F. Varoqueaux, R.B. Nehring, N. Brose, M.C. Wilson, and E. Neher. 2003. Differential control of the releasable vesicle pools by SNAP-25 splice variants and SNAP-23. Cell. 114:75-86. doi:10.1016/S0092-8674(03)00477-X

Sørensen, J.B., K. Wiederhold, E.M. Müller, I. Milosevic, G. Nagy, B.L. de Groot, H. Grubmüller, and D. Fasshauer. 2006. Sequential N- to C-terminal SNARE complex assembly drives priming and fusion of secretory vesicles. EMBO J. 25:955-966. doi:10.1038/sj.emboj.7601003

Stein, A., A. Radhakrishnan, D. Riedel, D. Fasshauer, and R. Jahn. 2007. Synaptotagmin activates membrane fusion through a $\mathrm{Ca} 2+-$ dependent trans interaction with phospholipids. Nat. Struct. Mol. Biol. 14:904-911. doi: $10.1038 / \mathrm{nsmb} 1305$

Südhof, T.C. 2004. The synaptic vesicle cycle. Annu. Rev. Neurosci. 27:509-547. doi:10.1146/annurev.neuro.26.041002.131412

Südhof, T.C., and J.E. Rothman. 2009. Membrane fusion: grappling with SNARE and SM proteins. Science. 323:474-477. doi:10.1126/science.1161748

Sutton, R.B., D. Fasshauer, R. Jahn, and A.T. Brunger. 1998. Crystal structure of a SNARE complex involved in synaptic exocytosis at 2.4 A resolution. Nature. 395:347-353. doi:10.1038/26412

Tang, J., A. Maximov, O.H. Shin, H. Dai, J. Rizo, and T.C. Südhof. 2006. A complexin/synaptotagmin 1 switch controls fast synaptic vesicle exocytosis Cell. 126:1175-1187. doi:10.1016/j.cell.2006.08.030

Verhage, M., and J.B. Sørensen. 2008. Vesicle docking in regulated exocytosis. Traffic. 9:1414-1424. doi:10.1111/j.1600-0854.2008.00759.x

Voets, T. 2000. Dissection of three Ca2+-dependent steps leading to secretion in chromaffin cells from mouse adrenal slices. Neuron. 28:537-545. doi:10.1016/S0896-6273(00)00131-8

Voets, T., E. Neher, and T. Moser. 1999. Mechanisms underlying phasic and sustained secretion in chromaffin cells from mouse adrenal slices. Neuron. 23:607-615. doi:10.1016/S0896-6273(00)80812-0

Voets, T., T. Moser, P.E. Lund, R.H. Chow, M. Geppert, T.C. Südhof, and E. Neher. 2001a. Intracellular calcium dependence of large dense-core vesicle exocytosis in the absence of synaptotagmin I. Proc. Natl. Acad. Sci. USA. 98:11680-11685. doi:10.1073/pnas.201398798

Voets, T., R.F. Toonen, E.C. Brian, H. de Wit, T. Moser, J. Rettig, T.C. Südhof, E. Neher, and M. Verhage. 2001b. Munc18-1 promotes large dense-core vesicle docking. Neuron. 31:581-591. doi:10.1016/ S0896-6273(01)00391-9

Wang, C.T., R. Grishanin, C.A. Earles, P.Y. Chang, T.F. Martin, E.R. Chapman, and M.B. Jackson. 2001. Synaptotagmin modulation of fusion pore kinetics in regulated exocytosis of dense-core vesicles. Science. 294:11111115. doi:10.1126/science. 1064002

Wang, C.T., J. Bai, P.Y. Chang, E.R. Chapman, and M.B. Jackson. 2006 Synaptotagmin-Ca2+ triggers two sequential steps in regulated exocytosis in rat PC12 cells: fusion pore opening and fusion pore dilation. J. Physiol. 570:295-307.

Weber, T., B.V. Zemelman, J.A. McNew, B. Westermann, M. Gmachl, F Parlati, T.H. Söllner, and J.E. Rothman. 1998. SNAREpins: minimal machinery for membrane fusion. Cell. 92:759-772. doi:10.1016/ S0092-8674(00)81404-X

Wei, S., T. Xu, U. Ashery, A. Kollewe, U. Matti, W. Antonin, J. Rettig, and E. Neher. 2000. Exocytotic mechanism studied by truncated and zero layer mutants of the C-terminus of SNAP-25. EMBO J. 19:1279-1289. doi:10.1093/emboj/19.6.1279

Weimer, R.M., J.E. Richmond, W.S. Davis, G. Hadwiger, M.L. Nonet, and E.M Jorgensen. 2003. Defects in synaptic vesicle docking in unc-18 mutants. Nat. Neurosci. 6:1023-1030. doi:10.1038/nn1118

Weninger, K., M.E. Bowen, U.B. Choi, S. Chu, and A.T. Brunger. 2008 Accessory proteins stabilize the acceptor complex for synaptobrevin, the 1:1 syntaxin/SNAP-25 complex. Structure. 16:308-320. doi:10.1016/ j.str.2007.12.010

Wiederhold, K., and D. Fasshauer. 2009. Is assembly of the SNARE complex enough to fuel membrane fusion? J. Biol. Chem. 284:13143-13152. doi:10.1074/jbc.M900703200

Wightman, R.M., J.A. Jankowski, R.T. Kennedy, K.T. Kawagoe, T.J. Schroeder, D.J. Leszczyszyn, J.A. Near, E.J. Diliberto Jr., and O.H. Viveros. 1991. Temporally resolved catecholamine spikes correspond to single vesicle 
release from individual chromaffin cells. Proc. Natl. Acad. Sci. USA. 88:10754-10758. doi:10.1073/pnas.88.23.10754

Wu, M.N., T. Fergestad, T.E. Lloyd, Y. He, K. Broadie, and H.J. Bellen. 1999. Syntaxin 1A interacts with multiple exocytic proteins to regulate neurotransmitter release in vivo. Neuron. 23:593-605. doi:10.1016/ S0896-6273(00)80811-9

Xu, T., T. Binz, H. Niemann, and E. Neher. 1998. Multiple kinetic components of exocytosis distinguished by neurotoxin sensitivity. Nat. Neurosci. 1:192-200. doi:10.1038/642

Xue, M., K. Reim, X. Chen, H.T. Chao, H. Deng, J. Rizo, N. Brose, and C. Rosenmund. 2007. Distinct domains of complexin I differentially regulate neurotransmitter release. Nat. Struct. Mol. Biol. 14:949-958. doi: $10.1038 / \mathrm{nsmb} 1292$

Yang, C., S. Mora, J.W. Ryder, K.J. Coker, P. Hansen, L.A. Allen, and J.E. Pessin. 2001. VAMP3 null mice display normal constitutive, insulin- and exercise-regulated vesicle trafficking. Mol. Cell. Biol. 21:1573-1580. doi:10.1128/MCB.21.5.1573-1580.2001

Zhang, X., M.J. Kim-Miller, M. Fukuda, J.A. Kowalchyk, and T.F. Martin. 2002. Ca2+-dependent synaptotagmin binding to SNAP-25 is essential for Ca2+-triggered exocytosis. Neuron. 34:599-611. doi:10.1016/ S0896-6273(02)00671-2 